\title{
The Management and Imaging of Vestibular Schwannomas
}

\author{
(1D)E.P. Lin and DB.T. Crane
}

\begin{abstract}
SUMMARY: Vestibular schwannomas are the most common cerebellopontine angle tumor. During the past century, the management goals of vestibular schwannomas have shifted from total resection to functional preservation. Current treatment options include surgical resection, stereotactic radiosurgery, and observation. Imaging has become a crucial part of the initial screening, evaluation, and follow-up assessment of vestibular schwannomas. Recognizing and understanding the management objectives, various treatment modalities, expected posttreatment findings, and complications allows the radiologist to play an essential role in a multidisciplinary team by providing key findings relevant to treatment planning and outcome assessment. The authors provide a comprehensive discussion of the surgical management, role of radiation therapy and observation, imaging differential, and pre- and posttreatment imaging findings of vestibular schwannomas.
\end{abstract}

ABBREVIATIONS: AAO-HNS = American Academy of Otolaryngology-Head and Neck Surgery; $\mathrm{CN}=$ cranial nerve; $\mathrm{CPA}=$ cerebellopontine angle; $3 \mathrm{D}$ SS-GRE = volumetrically acquired steady-state gradient-echo; IAC = internal auditory canal; $\mathrm{MF}=$ middle fossa craniotomy; $\mathrm{PF}=$ posterior fossa; RS = retrosigmoid craniotomy; SRS = stereotactic radiosurgery; TL = translabyrinthine craniotomy; VS = vestibular schwannoma

V estibular schwannomas (VSs) are benign neoplasms of the nerve sheath and account for $6 \%-8 \%$ of all intracranial tumors and $80 \%$ of cerebellopontine angle (CPA) tumors. ${ }^{1}$ VSs may remain within the internal auditory canal (IAC) or extend into the CPA. Symptoms are typically related to compression of adjacent cranial nerves (CNs), brain stem, or posterior fossa (PF) structures.

Imaging plays a central role in the screening and initial and follow-up assessment of VSs. Imaging can often differentiate VS from other entities such as facial nerve schwannoma, meningioma, epidermoid cyst, arachnoid cyst, aneurysm, and metastasis. ${ }^{2}$ MR imaging is the preferred technique and can provide exquisite tumor characterization, surgical planning, and posttherapeutic evaluation. ${ }^{3-5}$ Contrast-enhanced CT of the temporal bones can serve as an alternative if the patient cannot undergo MR imaging.

From the Departments of Imaging Sciences (E.P.L.) and Otolaryngology (B.T.C), University of Rochester Medical Center, Rochester, New York.

During preparation of this article, B.T.C. was supported by National Institute on Deafness and Other Communication Disorders grant R01 DC013580.

Paper previously presented in part at: Annual Midwest Head and Neck Imaging Meeting, March 5-6, 2016; Madison, Wisconsin, entitled "The Lateral Skull Base: Historical, Surgical and Radiologic Perspectives."

Please address correspondence to Edward P. Lin, MD, University of Rochester Medical Center, Department of Imaging Sciences, 601 Elmwood Ave, Box 648, Rochester, NY 14642; e-mail: Edward_Lin@URMC.rochester.edu

-- Indicates open access to non-subscribers at www.ajnr.org

http://dx.doi.org/10.3174/ajnr.A5213
The goals of VS management have shifted from total resection to functional preservation, particularly when the entire tumor cannot be safely resected with respect to cranial nerve preservation. ${ }^{6,7}$ Studies have revealed suboptimal postsurgical facial nerve function in gross total resection of large VSs. ${ }^{8,9}$ Depending on many factors, including patient age, tumor size and growth, and symptomatology, patients can choose surgery, radiation, or conservative management. Patients with neurofibromatosis type 2 , which is characterized by bilateral VSs, other schwannomas, meningiomas, ependymomas, and ocular abnormalities, are managed differently than those with sporadic unilateral VSs ${ }^{10}$ and will not be further discussed due to the scope of this topic.

Advances in surgical management of VS during the past century have defined lateral skull base approaches that are now applied in the management of other PF and skull base pathologies. Each approach offers different surgical exposures, benefits, and disadvantages. Stereotactic radiosurgery (SRS) is an acceptable option, with similar rates of tumor control and a low risk for permanent facial nerve palsy. Observation is a reasonable option for smaller tumors, older patients, and those with major comorbidities.

This article will review the treatment objectives, surgical approaches, and expected posttreatment findings and complications of VS management. Knowledge of these advances enhances the radiologist's ability to participate in a multidisciplinary team 
by providing key information relevant to the treatment planning and outcome.

\section{Background}

VS, often referred to as "acoustic neuroma," most commonly originates from the vestibular division of the vestibulocochlear nerve sheath, often at the transition from central to peripheral myelin near the vestibular ganglion at the IAC fundus.

Inactivation of the neurofibromin 2 gene has been implicated in sporadic and neurofibromatosis type $2 \mathrm{VS}^{11}{ }^{11}$ This gene is located on chromosome 22 and produces schwannomin (merlin), a tumor-suppressor cell membrane-related protein. Perineural elements of Schwann cells, with areas of dense (Antoni A) and sparse (Antoni B) cellularity, are found histopathologically. Immunohistochemical staining is typically positive for S-100 protein.

VS presents at a median age of 50 years and is unilateral in $>90 \%$ of patients, with an equal incidence on the left and right. Symptomatology is often related to cranial neuropathies. Patients more often present with chronic asymmetric sensorineural hearing loss than tinnitus or unsteadiness. True vertigo, sudden hearing loss, facial pain, numbness, and weakness are uncommon due to slow tumor growth. Sensorineural hearing loss is confirmed by audiometry and brain stem-evoked response audiometry, with findings that are abnormal in $>90 \%-95 \%$ of patients with VS. ${ }^{12}$

\section{Historical Perspective}

Charles McBurney performed the first suboccipital plate removal in $1891,{ }^{13}$ though the patient died soon after. A few years later, Sir Charles Ballance in England was the first to successfully remove a VS via a suboccipital plate and blunt dissection of a CPA mass. ${ }^{14}$ Surgical outcome, in general, remained poor in the late 1800 s, with a surgical mortality rate of $80 \%$ and high postoperative morbidity. ${ }^{15}$

By observing the radiographic properties of bowel gas, Walter Dandy injected air into the subarachnoid spaces, creating the first pneumoencephalographic images in the early 1900s. ${ }^{16}$ Pneumoencephalography allowed the localization of intracranial masses by observing the mass effect on the ventricles and the direction of the midline shift. ${ }^{17}$

Advances in neurosurgery in the early 1900 s led to a decrease in surgical mortality to $20 \%$. Harvey Cushing promoted a bilateral suboccipital approach and removal of the tumor core while leaving the tumor capsule in place to improve $\mathrm{CN}$ preservation. ${ }^{18}$

In 1961, William House introduced the operative microscope in temporal bone surgeries, allowing exquisite visualization and improved preservation of the facial nerve. ${ }^{19}$ William House fostered collaboration with the neurosurgeon William Hitselberger, establishing a multidisciplinary approach to VS resections. William House re-introduced the translabyrinthine approach as an option for patients with unserviceable hearing. ${ }^{20}$ In 1979, Tomas Delgado performed the first intraoperative $\mathrm{CN}$ monitoring, which improved $\mathrm{CN}$ preservation. ${ }^{21}$

During the same period, Lars Leksell in Sweden invented the gamma knife in 1968 and performed the first SRS on a VS in $1969 .^{22,23}$ SRS was later confirmed as an effective alternative to surgery in the treatment of VS. ${ }^{24}$
Radiographically, positive-contrast cisternography in the 1960s improved delineation of PF structures. ${ }^{25}$ Polytome-pantopaque allowed depiction of even smaller intracanalicular VSs. ${ }^{26}$ The advent of cross-sectional imaging in the 1970s now provides noninvasive means of detecting and evaluating small VSs.

\section{Natural History of VS}

More than half of all VSs grow at an average of 2-4 mm/year, whereas $<10 \%$ regress. ${ }^{27}$ One study revealed that extrameatal tumors $(28.9 \%)$ were more likely to grow compared with intrameatal tumors (17\%) and a larger percentage of tumors grew early on after detection. ${ }^{28} \mathrm{~A}$ VS of $>2 \mathrm{~cm}$ is more likely to grow compared with a smaller VS. ${ }^{29,30}$ Growth rates of $>2 \mathrm{~mm} /$ year are associated with decreased rates of hearing preservation compared with slower growth rates. ${ }^{31}$

\section{Surgical Management of VS}

Surgical objectives have shifted from total resection to long-term functional preservation. ${ }^{6,7}$ Subtotal resection followed by observation or SRS, particularly for a large VS, can achieve long-term tumor control with improved CN preservation. ${ }^{6,7,32}$ In general, a small-to-medium VS of $<3 \mathrm{~cm}$ is managed differently from a large VS because surgery is often favored over SRS for a large VS. While some investigators have experience in successfully treating large VSs with SRS, ${ }^{33}$ others believe that SRS may risk compressive ischemia of CN VII and brain stem compression in the treatment of a large VS. ${ }^{34,35}$ The optimal treatment of a VS, particularly a small-to-medium one, remains controversial, and treatment technique preference will vary from center to center.

Gross total resection is offered to younger patients with persistent dizziness, patients with small anatomically favorable tumors and good hearing, cystic tumors, and larger tumors with symptoms related to mass effect. ${ }^{35}$ Surgery, as opposed to SRS, provides a definitive histopathologic diagnosis. Due to the postradiation effects on tissue, SRS following surgical resection is more favorable than surgical resection following SRS. Surgery, however, is associated with a greater risk of permanent facial nerve palsy compared with SRS. ${ }^{35}$ Other risks of surgical resection include iatrogenic hearing loss, CSF leak, meningitis, headache, and anesthesia-related complications. Following gross total resection, the 5-year recurrence rate of VS has been reported as up to $10 \%{ }^{7}$ The 10 -year tumor control rates for gross total and subtotal resection are $78 \%$ and $82 \%$, respectively. ${ }^{7}$

\section{Surgical Approaches}

VS may be approached by a translabyrinthine (TL), retrosigmoid (RS), or middle fossa (MF) craniotomy. The indications, advantages, and disadvantages of each are summarized in Table 1.

\section{Translabyrinthine Craniotomy}

The TL is a posterior approach through the mastoid temporal bone, anterior to the sigmoid sinus (Fig 1). Following a simple mastoidectomy, the vertical facial nerve canal is skeletonized and a labyrinthectomy is performed, allowing access to the IAC behind the vestibule (Fig 1). ${ }^{36}$ Access to the CPA can be gained by removing bone posterior to the porus acusticus. While one performs facial nerve monitoring, the tumor is debulked and micro- 
Table 1: Indications, benefits, and disadvantages of lateral skull base approaches for VS resection

\begin{tabular}{|c|c|c|c|}
\hline & Translabyrinthine & Retrosigmoid & Middle Fossa \\
\hline Indications & $\begin{array}{l}\text { Unserviceable hearing; any IAC } \\
\text { or CPA VS }\end{array}$ & $\begin{array}{l}\text { VS with large CPA component; medial } \\
\text { IAC VS }\end{array}$ & $\begin{array}{l}\text { Small lateral IAC VS }(<0.5 \mathrm{~cm}) \\
\text { small medial IAC VS with }<1 \\
\text { cm CPA component }\end{array}$ \\
\hline Advantages & Minimal brain retraction & $\begin{array}{l}\text { Panoramic CPA exposure; better facial } \\
\text { nerve and hearing preservation for } \\
\text { medial VS }\end{array}$ & Better exposure, lateral IAC \\
\hline Disadvantages & $\begin{array}{l}\text { Complete hearing loss; difficult } \\
\text { approach for CPA VS ventral } \\
\text { to porus acusticus; risk for } \\
\text { facial nerve injury }\end{array}$ & $\begin{array}{l}\text { Limited access to lateral IAC; potential } \\
\text { for cerebellar and brain stem injury }\end{array}$ & $\begin{array}{l}\text { Limited PF access; temporal lobe } \\
\text { retraction; risk for facial nerve } \\
\text { injury }\end{array}$ \\
\hline
\end{tabular}
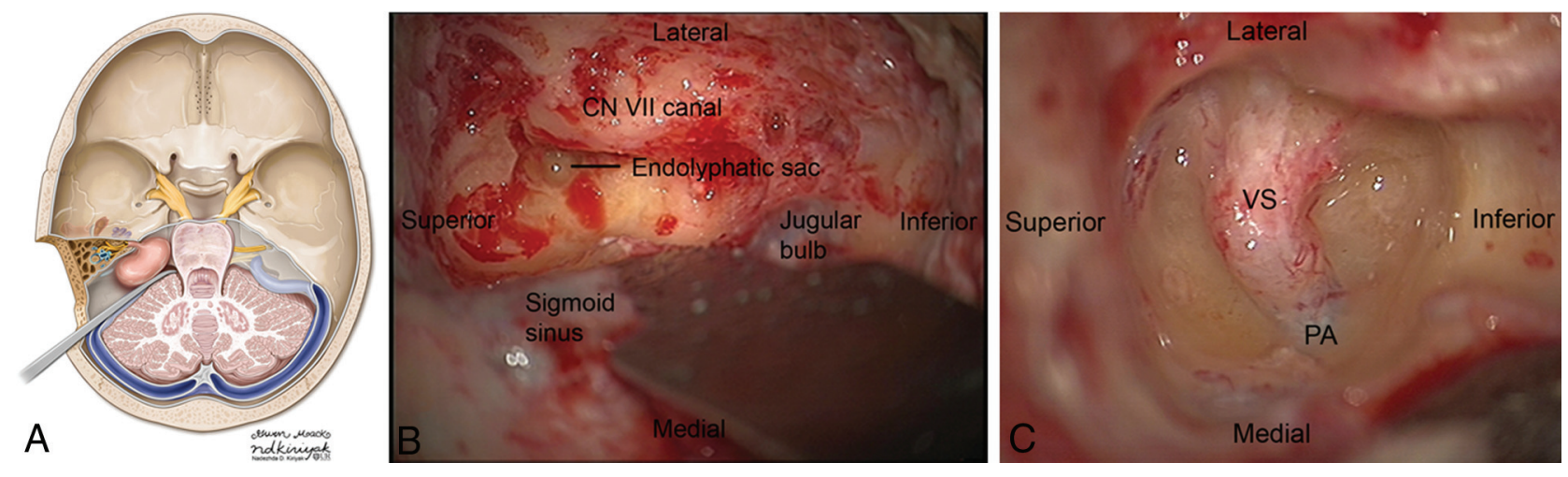

FIG 1. Axial illustration $(A)$ of a translabyrinthine craniotomy demonstrates exposure of the IAC and CPA, and it may be performed with or without cerebellar retraction. Intraoperative images just before $(B)$ and following $(C)$ the labyrinthectomy demonstrate exposure to the intracanalicular vestibular schwannoma. PA indicates porus acusticus. $A$ is reproduced with permission from the University of Rochester.
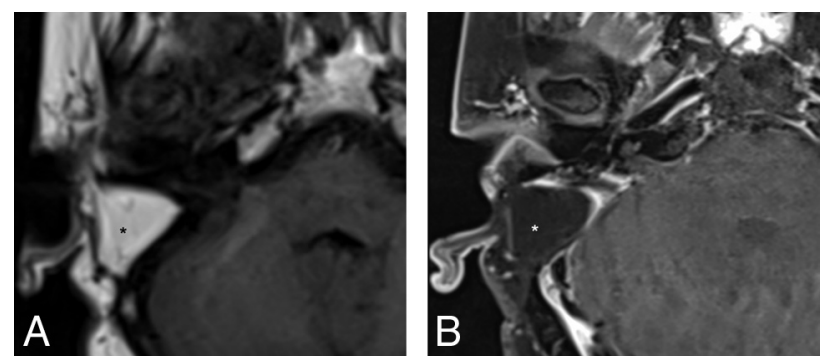

FIG 2. Precontrast axial TIWI $(A)$ and postcontrast axial TIWI with fat-suppression $(B)$ demonstrate typical postoperative findings following a translabyrinthine craniotomy, with abdominal fat packing within the mastoidectomy defect (asterisk). Linear enhancement along the mastoidectomy bed reflects postsurgical changes without evidence of recurrent tumor within the IAC.

dissected. The craniotomy is closed by placing the temporalis fascia at the aditus ad antrum and abdominal fat packing within the mastoidectomy defect. Fat is preferred to muscle because fat is easily obtainable and associated with less morbidity. The fat signal can be advantageously suppressed on follow-up contrast-enhanced MR imaging (Fig 2).

The TL allows adequate exposure of the IAC and PF with minimal brain retraction. The RS approach may be preferred if a large PF component is present. Due to the complete loss of hearing, TL is reserved only for patients with unserviceable hearing or poor hearing prognosis.

\section{Retrosigmoid Craniotomy}

$\mathrm{RS}$ is a posterior approach that allows panoramic visualization of the CPA (Fig 3). Following a suboccipital craniotomy posterior to the sigmoid sinus, the cerebellum is retracted medially, exposing the CPA mass and neurovascular structures (Fig 3). The facial nerve is identified, and the CPA component is dissected. The intrameatal component can then be accessed and removed by drilling the posterior meatal lip (Fig 3). Tumor infiltration of the cochlear nerve, poor preoperative hearing, and larger tumor size decrease the likelihood of hearing preservation. ${ }^{36}$

RS permits resection of large extrameatal and small medial intrameatal tumors while allowing hearing preservation. ${ }^{37-39}$ The RS approach to intrameatal VS can be limited by a high-riding jugular bulb or obstructed by the labyrinth. ${ }^{39}$ Cerebellum retraction may lead to parenchymal injury. Early postoperative headaches following RS may be higher than in TL, ${ }^{40}$ possibly secondary to subarachnoid bone dust dissemination or the use of a titanium plate.

\section{Middle Fossa Approach}

The MF is a lateral approach to the IAC (Fig 4). A temporal craniotomy is performed above the external auditory canal (Fig 4). The dura is elevated off the skull base, and the temporal lobe is retracted superiorly. Landmarks for this approach include the arcuate eminence and the greater superficial petrosal nerve. The IAC can then be accessed from above (Fig 4), and the tumor can be resected following microdissection of the facial and cochlear nerves. Bone wax is used to fill exposed mastoid air cells.

The MF is best for small lateral IAC tumors, particularly those that extend to the IAC fundus, when hearing preservation is a treatment objective. MF is not typically attempted on tumors with a $>1-\mathrm{cm}$ CPA component due to limited exposure to the PF, ${ }^{36}$ though some surgeons have had success with larger tumors via 

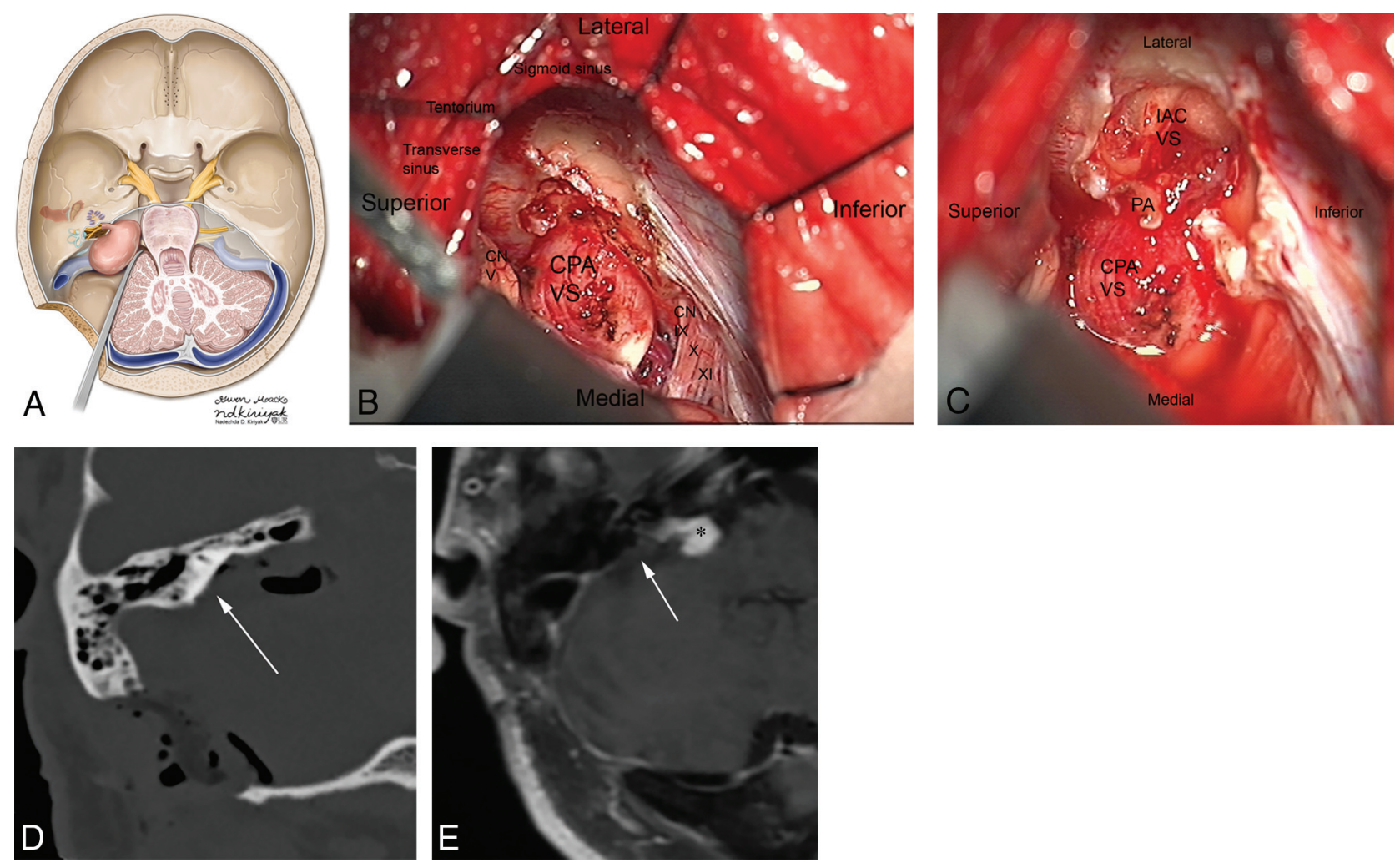

FIG 3. Axial illustration $(A)$ of a retrosigmoid craniotomy reveals a typical exposure of the CPA and lateral IAC by drilling through the posterior meatal lip. Intraoperative image (B) reveals excellent exposure of the CPA VS and adjacent cranial nerves (CNs V, IX-XI). A second intraoperative image $(C)$ following removal of the posterior face of the IAC wall exposes the intrameatal component of the VS (IAC VS). Immediate postoperative noncontrast axial CT $(D)$ and a contrast-enhanced TIWI with fat-suppression $(E)$ demonstrate a retrosigmoid craniectomy with a defect in the posterior meatal lip (arrow) and a residual extrameatal enhancing VS on the contrast-enhanced TIWI. $A$ is reproduced with permission from the University of Rochester.
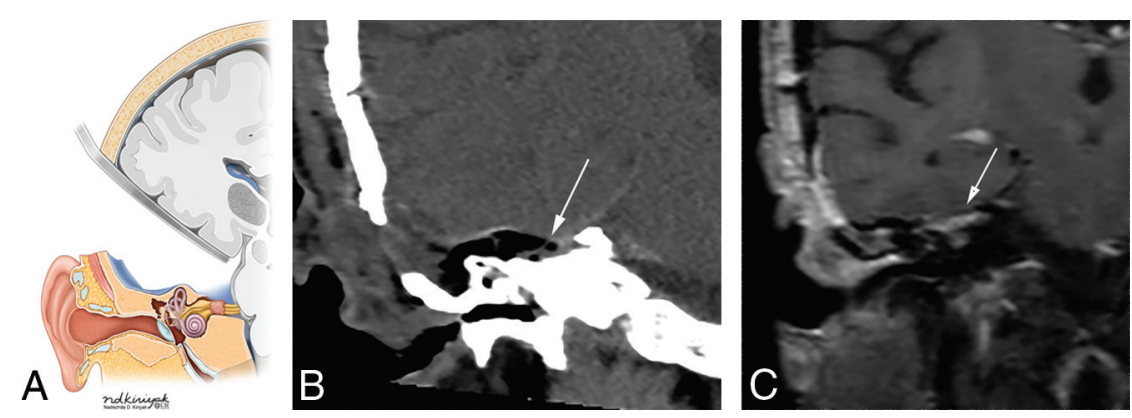

FIG 4. Coronal illustration $(A)$ of a middle fossa craniotomy demonstrates retraction of the temporal lobe and drilling of the petrous apex over the superior semicircular canal to provide access to the IAC. Postoperative coronal reformation of noncontrast CT (B) and coronal TIWI with fat suppression $(C)$ reveal a temporal craniotomy and absence of the IAC roof (arrows), through which the VS was accessed, and linear enhancement within the IAC, which reflects expected postsurgical changes without evidence of residual tumor. $A$ is reproduced with permission from the University of Rochester.

this approach. Temporal lobe retraction is associated with a small risk of seizures, aphasia, and stroke. MF is optimal for a VS arising from the superior division, which displaces the facial nerve anteriorly.

\section{Radiation Therapy}

Radiation can be performed by using SRS, stereotactic radiation therapy, and conventional fractionated radiation therapy. SRS is the most commonly used technique and converges multiple beams onto a delineated volume by using cross-sectional imaging to minimize injury to adjacent tissues. An initial SRS dosage of a 16- to 20-Gy marginal dose achieved a $98 \%$ tumor control rate but resulted in unacceptably high rates of early hearing loss (60\%) and facial and trigeminal neuropathies $(33 \%) .^{24,41-43}$

SRS dose reductions from 13-14 to 11-12 Gy in more recent years have resulted in $>90 \%$ tumor control rates and $<1 \%$ risk for permanent facial nerve palsies. ${ }^{44,45}$ Slightly lower doses of 12-13 Gy can be preferentially given to patients with serviceable hearing, and slightly higher doses of 13-14 Gy, to patients with poor hearing prognosis. ${ }^{43}$

While hearing preservation rates of $60 \%-70 \%$ were initially reported, longer term follow-up studies of up to 10 years revealed progressive hearing deterioration in most patients. Serviceable hearing was preserved in only $23 \%-24 \%$ patients at 10 years. ${ }^{46-48}$ Older age, larger tumors, and poorer pretreatment hearing were found to be risk factors for progressive posttreatment hearing loss. ${ }^{46,48,49}$ Reducing the cochlear dose to improve hearing preservation continues to be controversial and has not been confirmed to reduce long-term hearing deterioration. ${ }^{50}$

AJNR Am J Neuroradiol 38:2034-43 Nov 2017 www.ajnr.org 

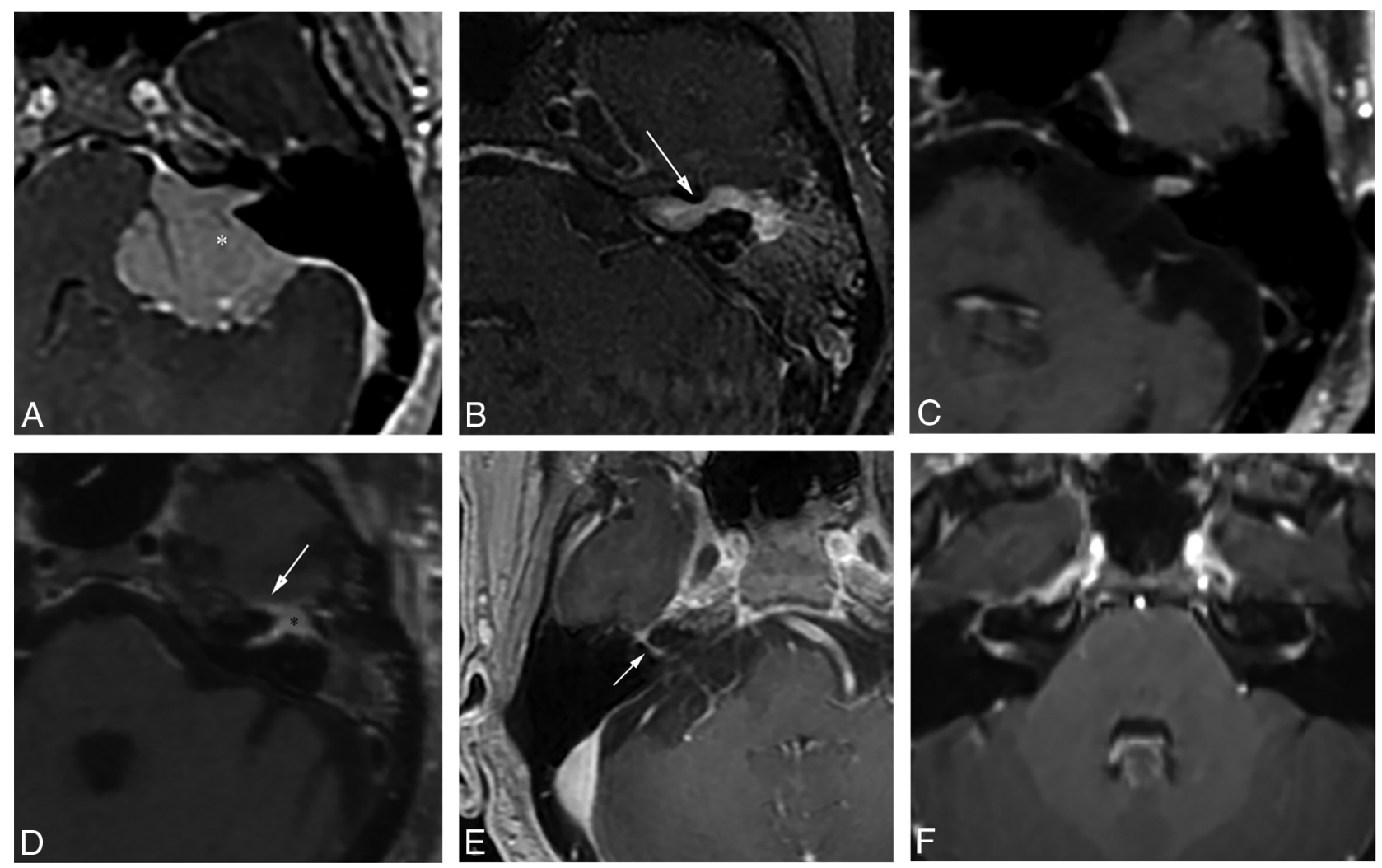

FIG 5. Examples of various enhancing IAC and CPA masses on contrast-enhanced TIWI with fat-suppression $(B-D$, and $F)$ and $3 D$ echo-spoiled gradient-echo images ( $A$ and $E$ ). A, A large CPA meningioma, located eccentric to the porus acusticus (the asterisk denotes the tumor midline), extends into the IAC without the associated bony expansion often seen with VS (see Fig 6). B, An enhancing facial nerve schwannoma within the IAC extends into the labyrinthine segment (arrow), which differentiates a facial nerve from a vestibular schwannoma, as well as into the anterior genu and tympanic segments. C, A small enhancing metastatic lesion within the IAC in a patient with non-small cell lung cancer extends into the IAC fundus, labyrinthine, anterior genu, and tympanic segments. $D$, Perineural spread along the intratemporal and intracanicular segments of the facial nerve in a patient with squamous cell carcinoma of the periauricular skin (the asterisk indicates the anterior genu; arrow, the greater superficial petrosal nerve). E, An ill-defined tuft of enhancement within the IAC fundus extending into the labyrinthine segment (arrow) and anterior genu of the facial nerve in a patient with right Bell palsy. F, Bilateral ill-defined enhancement of the distal IAC bilaterally extending into the labyrinthine segment and anterior genu of the facial nerve canal in a patient with neurosarcoidosis.

\section{Observation}

Observation is offered to select patients who are typically followed with serial MR imaging every 6-12 months. Indications include patients older than 60 years of age with significant comorbidity, small tumor size, and absence of symptoms. Patients who are at risk for hearing loss from other causes or prefer observation may also be offered conservative management. Observation, however, is associated with progressive hearing loss, due to the slow growth of most of these tumors. Tumor growth of $>2.5 \mathrm{~mm} /$ year is associated with higher rates of hearing deterioration compared with slower growing tumors. ${ }^{31}$ If hearing preservation remains a treatment objective, earlier intervention may lead to a better outcome. $^{51}$

\section{Imaging}

Differential. VS is the most common extra-axial CPA mass (70\%-80\%), followed by meningiomas (10\%-15\%) and epidermoid cysts (5\%). ${ }^{52} \mathrm{CPA}$ meningiomas are dural-based enhancing masses that grow along the petrous ridge and can extend into the IAC. Large meningiomas are often located asymmetrically relative to the IAC (Fig 5). Meningiomas may contain intralesional calcifications, and a dural tail and can result in changes of the under- lying bone, as well as peritumoral vasogenic edema if mass effect is present.

Other enhancing lesions of the IAC and CPA include neoplastic etiologies, such as leptomeningeal metastasis, lymphoma, meningeal melanocytoma, or malignant melanoma; facial nerve perineural spread; inflammatory processes, such as Bell palsy and neurosarcoidosis; and aneurysms (Fig 5). Identifying enhancement of the labyrinthine facial nerve can distinguish CN VII pathologies from a VS (Fig 5). Aneurysms demonstrate nodular enhancement but are contiguous with vascular structures and often exhibit flow voids, eccentric peripheral enhancement, and pulsation artifacts on MR imaging.

Because a VS can contain cystic components, the radiologist should also be aware of other cystic lesions of the CPA. The characteristic MR signal and enhancement patterns of these lesions, however, should not lead to any confusion among these entities. Epidermoid cysts are nonenhancing cysts of congenital ectodermal elements that encase or displace neurovascular structures and extend into the cerebellar fissures with ill-defined margins. Relative to CSF, these cysts demonstrate similar attenuation on CT, isointense-to-slightly hyperintense signal to CSF on T1WI and T2WI, and incomplete suppression on T2 FLAIR. The presence of 

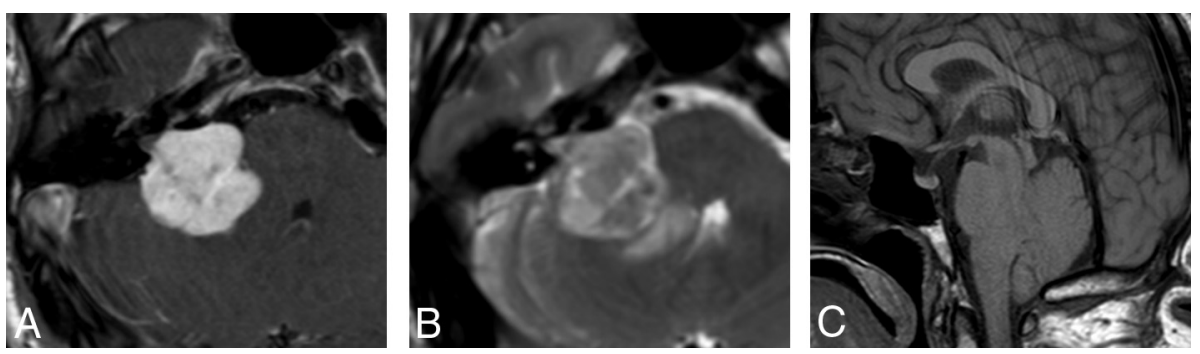

FIG 6. Contrast-enhanced axial TIWI (A), axial T2WI (B), and sagittal TIWI (C) reveal a large right CPA VS with asymmetric enlargement of the IAC, brain stem and cerebellar compression, peritumoral edema, and tonsillar herniation.

Table 2: A sample MR imaging protocol for the evaluation of $\mathbf{V S}^{\mathrm{a}}$

\begin{tabular}{|c|c|c|c|c|c|c|}
\hline Sequence & $\begin{array}{l}\text { FOV } \\
(\mathrm{cm})\end{array}$ & $\begin{array}{l}\text { Thickness and } \\
\text { Spacing (mm) }\end{array}$ & $\begin{array}{c}\text { TR (ms) } \\
\text { (or Flip Angle) }\end{array}$ & $\begin{array}{c}\mathrm{TE} \\
(\mathrm{ms})\end{array}$ & Matrix & Comments \\
\hline Sag TI FLAIR & 24 & $5 \times 1$ & 2800 & 9 & $320 \times 224$ & (TI $858 \mathrm{~ms})$ \\
\hline Ax DTI & 26 & $3 \times 0$ & 8000 & Min & $128 \times 128$ & \\
\hline Sag 3D T2 FLAIR FS & 27 & 1.4 & 7600 & 120 & $256 \times 256$ & With $\mathrm{Ax}$ and Cor reformations \\
\hline Ax T2 FLAIR & 24 & $5 \times 1$ & 9500 & 125 & $352 \times 224$ & Alternative to 3D T2 FLAIR (TI = $2250 \mathrm{~ms}$ ) \\
\hline $\mathrm{Ax} T 2 \mathrm{FS}$ & 18 & $3 \times 0.5$ & 4917 & 87 & $320 \times 320$ & Through PF only \\
\hline Ax FIESTA & 18 & 0.8 & $\left(45^{\circ}\right)$ & Min & $300 \times 300$ & With $A x$ and Sag oblique reformations \\
\hline Ax SWAN or SWI & 25 & 2 & $\operatorname{Min}\left(15^{\circ}\right)$ & 25 & $320 \times 224$ & Optional \\
\hline Sag 3D TI FS + C & 25 & 1.2 & 600 & Min & $288 \times 288$ & With $\mathrm{Ax}$ and Cor reformations \\
\hline$A \times 3 D S P G R+C$ & 25 & 1.5 & $\left(20^{\circ}\right)$ & Min & $320 \times 224$ & For treatment planning; nonangled orthogonal $\mathrm{Ax}$ \\
\hline $\mathrm{AxT} \mathrm{TS}+\mathrm{C}$ & 18 & $3 \times 0.5$ & 2723.5 & 22 & $320 \times 320$ & Alternative to $3 \mathrm{D} T 1 \mathrm{FS}+\mathrm{C}(\mathrm{TI}=111 \mathrm{~ms})$ \\
\hline Cor $\mathrm{TTFS}+\mathrm{C}$ & 18 & $3 \times 0.5$ & 2475 & Min & $383 \times 224$ & Alternative to $3 \mathrm{D} T 1 \mathrm{FS}+\mathrm{C}(\mathrm{TI}=111 \mathrm{~ms})$ \\
\hline
\end{tabular}

Note:-SPGR indicates echo-spoiled gradient echo; FS, fat suppression; C, contrast; Sag, sagittal; Ax, axial; Cor, coronal; SWAN, T2 star-weighted angiography; Min, minimum ${ }^{a}$ Except for the axial 3D SPGR $+C$, all sequences are referenced to the anterior/posterior commissure line. An axial T2 FLAIR can be performed instead of the sagittal 3D T2 FLAIR. An axial and coronal T7 FS $+C$ can be performed in lieu of a sagittal 3D T FS $+C$.

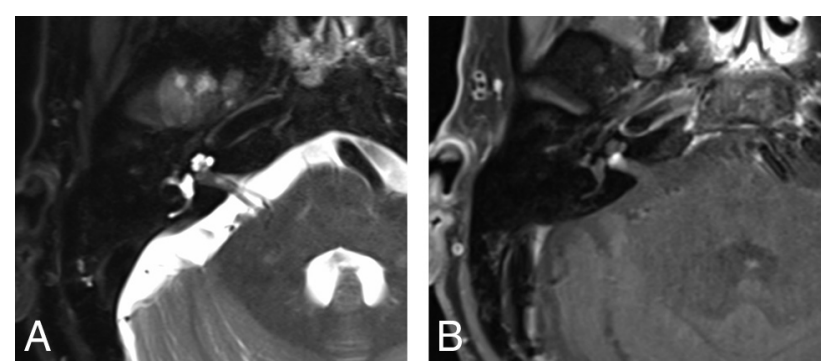

FIG 7. Precontrast axial T2WI (A) and postcontrast axial TIWI (B) demonstrate a small intracanalicular VS with lateral extension into the IAC fundus and the modiolus, which is associated with a decreased rate of hearing preservation.

diffusion restriction differentiates epidermoid from arachnoid cysts, which follow CSF signal on all sequences. Arachnoid cysts do not enhance, and they displace rather than engulf adjacent structures. Other uncommon cysts include dermoid cysts, neurocysticercosis, and neuroenteric cysts.

Initial Assessment. CT can detect moderate-large VSs, though small intracanalicular tumors can be missed. On CT, a solid VS is isoattenuating relative to the cerebellar parenchyma and typically enhances. Unlike a meningioma, a VS does not have calcifications.

$\mathrm{CT}$ is advantageous in assessing bony anatomy and pathologic changes. Unlike meningiomas, a moderate-large VS tends to expand the IAC (Fig 6), which may reflect tumor aggressiveness. ${ }^{53}$ IAC expansion is associated with poorer preoperative hearing and postoperative hearing function..$^{53}$ Because the cochlear nerve is often located anterior or inferior to the tumor, larger tumors extending in this direction may encapsulate, infiltrate, or stretch the nerve. ${ }^{37,53}$ The facial nerve can be affected by anterior extension of the tumor, though it appears to be more resilient than the cochlear nerve. ${ }^{53}$

Due to superior contrast resolution, MR imaging is now the standard of care in evaluating VS. A sample MR imaging protocol used in the evaluation of CPA masses is included in Table 2. VS is typically $\mathrm{T} 1$ isointense relative to the cerebellar parenchyma and demonstrates avid enhancement on postcontrast T1WI (Fig 6). A VS may contain intralesional hemorrhage, which may exhibit T1 hyperintense signal and susceptibility artifacts on $\mathrm{T}^{\star}$ gradientecho sequences. A larger VS often demonstrates inhomogeneous enhancement secondary to intralesional hemorrhage and cysts. Concerning features include larger size, brain stem or cerebellar compression, peritumoral edema, hydrocephalus, and tonsillar herniation (Fig 6). Enhancement may extend into the modiolus secondary to cochlear infiltration (Fig 7), which decreases the rate of hearing preservation.

Cystic VSs are a subtype that accounts for approximately $10 \%$ of all VSs and are associated with higher degrees of hearing loss. ${ }^{54}$ VS cysts are thought to arise from recurrent microbleeding or osmosis-induced expansion of CSF trapped in arachnoid tissue, ${ }^{54}$ leading to T2 hyperintense signal and variable T1 signal (Fig 7). Enhancement of the cyst wall differentiates a cystic VS from an arachnoid or epidermoid cyst, the latter of which demonstrates diffusion restriction. Cystic VS may rapidly expand, leading to brain stem and cerebellar compression, edema, and hydrocephalus. ${ }^{55}$ Surgical intervention is favored over SRS in the management of cystic VS because cystic VSs may respond poorly and unpredictably to SRS. ${ }^{56,57}$ In 1 study, $6.4 \%$ of cystic VSs initially treated with radiation therapy required surgical intervention. ${ }^{57}$ 
Cystic VSs are considered more aggressive, with shorter symptomatic periods before presentation. They may surround and adhere to neurovascular structures as well as the more hypervascular solid component of the mass, leading to a less favorable surgical outcome. ${ }^{55}$ Subtotal resection of cystic VS is sometimes advocated, particularly if there are peripherally located thin-walled cysts, ${ }^{55}$ which should be emphasized in radiologic reporting (Fig 8).

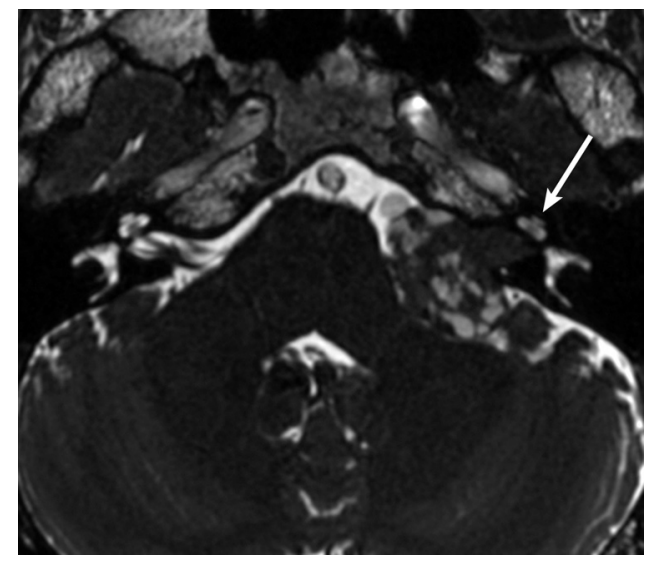

FIG 8. Axial FIESTA reveals a large left CPA VS with multiple superficial cysts, which may indicate increased adherence to neurovascular structures and lead to a more difficult surgical resection. Note asymmetric decreased T2 signal within the left cochlea (arrow) compared with the right.
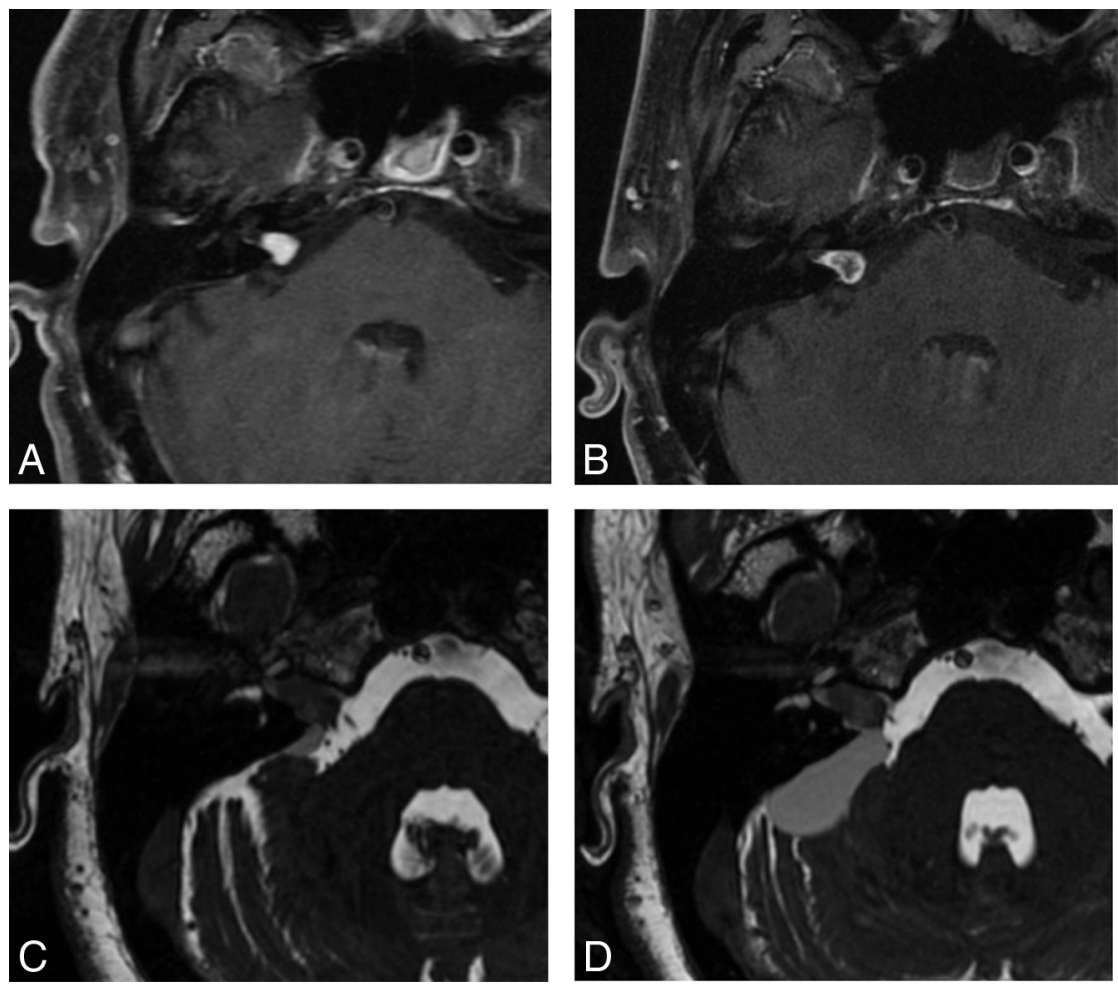

FIG 9. Two examples of post-SRS imaging. Postcontrast axial TIWI with fat suppression in a patient before $(A)$ and following $(B)$ SRS reveals decreased enhancement centrally within the tumor on posttherapeutic imaging $(B)$, confirming a positive response to SRS. Two axial FIESTA images ( $C$ and $D$ ) obtained during 2 consecutive follow-up examinations in a 2-year period demonstrate interval enlargement of the cystic component within the right CPA associated with a predominantly intrameatal VS following radiation therapy. The cystic component was later resected (not shown).
High-resolution volumetrically acquired steady-state gradient-echo (3D SS-GRE) sequences with heavily T2-weighted signal provide exquisite detail of the location and morphology of the mass, the presence of decreased labyrinthine signal, the course of neighboring $\mathrm{CNs}$ in relation to the mass, and the relationship of the labyrinth to the posterior meatal lip. Identifying CSF lateral to an intracanalicular mass near the IAC fundus on 3D SS-GRE or contrast-enhanced T1WI is a favorable prognostic finding because involvement of the IAC fundus is associated with decreased rates of hearing preservation (Fig 7). ${ }^{58}$ Decreased labyrinthine signal of 3D SS-GRE on initial imaging is associated with lower rates of posttreatment hearing preservation (Fig 8). ${ }^{59}$

Sagittal-oblique reformations of 3D SS-GRE sequences allow detailed assessment of the facial nerve course relative to a mass. A VS arising from the superior division of the vestibular nerve will often displace the facial nerve anteriorly, whereas one arising from the inferior division will displace the facial nerve more superiorly. The location of the facial nerve in relation to the VS influences the surgical approach chosen. Facial nerves that are displaced superiorly by the VS may be more easily injured with a TL or MF approach, leading the surgeon to favor the RS.

Because the posterior meatal lip is drilled to access the IAC in the RS approach, this region is carefully evaluated preoperatively by either CT or MR imaging. Pneumatized air cells in this region may lead to a postsurgical CSF fistula. ${ }^{53}$ A high-riding jugular bulb or jugular bulb diverticulum within the posterior meatal lip may potentially lead to vascular injury. Portions of the labyrinthine lying medial to the fundus-sinus line (the line from the sigmoid sinus to the IAC fundus) pose a higher risk for fenestration than those located laterally. ${ }^{53}$

An abbreviated noncontrast MR imaging with 3D SS-GRE has been proposed as an inexpensive screening examination to exclude an IAC mass. ${ }^{60}$ This study reported $100 \%$ sensitivity with high specificity and advocated adding a coronal T2WI to reduce false-positive/ -negative examination findings secondary to volume averaging and banding artifacts, which could occur if relying solely on 3D SS-GRE. ${ }^{60}$ An abbreviated noncontrast screening MR imaging, however, may not identify etiologies that are better depicted with contrast-enhanced MR imaging, such as other neoplastic and inflammatory conditions discussed above.

Increased labyrinthine T2 FLAIR hyperintense signal has been detected in patients with various pathologies, including VS, meningiomas, Meniére disease, Ramsay Hunt syndrome, otosclerosis, and sudden idiopathic sensorineural hearing loss. ${ }^{61-63}$ The T2 FLAIR hyperintense cochlear signal in patients with VS is attributed to increased pro- 
tein content within the perilymph, ${ }^{61,64}$ which may be secondary to tumor compression of the cochlear nerve, resulting in interference with neuroaxonal transport of proteins. ${ }^{61} 3 \mathrm{D}$-FLAIR sequences can optimally detect cochlear T2 FLAIR hyperintense signal. ${ }^{63,65,66}$ Kim et al $^{65}$ reported a significant correlation between the T2 FLAIR hyperintense cochlear signal and the degree of hearing impairment in patients with intracanalicular VS. This retrospective study, however, did not specify whether the 3DFLAIR sequence was performed consistently before or following intravenous contrast administration. Two smaller retrospective studies reported no correlation and a weak correlation between postcontrast T2 FLAIR hyperintense signal and the level of hearing impairment in patients with VS. ${ }^{63,66}$ Additional studies should be performed to further clarify the significance of the T2 FLAIR hyperintense cochlear signal in VS.

\section{Follow-Up Assessment}

Objectives of follow-up imaging include identification of residual/recurrent tumor, assessment of tumor size, response to radiation therapy, and the presence of posttherapeutic complications. Residual tumor is best assessed with a fat-suppressed contrastenhanced T1WI, because the signal from fat packing can be nullified (Fig 2). Because the goals of therapy have shifted from total resection to functional preservation, residual tumor is often intentionally left behind in areas near the facial nerve. The presence of residual enhancing tumor is not uncommon and may be followed with serial imaging and further treated with SRS (Fig 3). A residual mass tends to contract and become more rounded within 6-12 months of completion of SRS.

Standardized methods of tumor reporting and measurements have been promoted by national organizations, such as the American Academy of Otolaryngology-Head and Neck Surgery (AAOHNS) in $1995^{67}$ and the Consensus Meeting on Systems for Reporting Results in Acoustic Neuroma in 2003, ${ }^{68}$ though no single method has been clearly adopted. VS should be described as intracanalicular, extrameatal, or intrameatal and extrameatal, and cross-sectional measurements should be specific for each component. Growth tends to be the greatest in the extrameatal component, and recommendations have focused on the extrameatal measurements. The AAO-HNS has recommended the square root product of the extrameatal anteroposterior $\times$ medial lateral diameters, with the anteroposterior diameter measured parallel to the petrous ridge. ${ }^{67}$ The Consensus Meeting in 2003 favored using the maximum extrameatal diameter, which, by itself, sufficiently reflected growth of the tumor. ${ }^{68}$ One study has found the AAOHNS methodology to be preferable because tumors tend to grow in both anteroposterior and ML directions. ${ }^{69}$

Immediately following SRS, the tumor may increase in size due to intralesional edema, which rarely indicates treatment failure. ${ }^{70}$ In 1 study, 5\% of tumors enlarged following SRS but remained stable on subsequent imaging. ${ }^{71}$ Most VSs treated with SRS will subsequently decrease or remain stable in size, reflecting adequate tumor control. ${ }^{43}$ Decreased enhancement centrally within the tumor is considered a positive response to therapy and is typically seen within 6 months following SRS (Fig 9). ${ }^{43}$ Radiation therapy may uncommonly induce cystic degeneration that may be secondary to microbleeding, increased vascular permea- bility, or scarring of arachnoid adhesions (Fig 9). ${ }^{72}$ The potential for postradiation cystic degeneration is one rationale for treating cystic VS initially with surgical resection.

While uncommon, dural sinus thrombus may be seen following an RS or TL approach secondary to injury of the sigmoid sinus and may result in venous congestion or infarction. Brain retraction during an RS or MF approach may result in edema or ischemia of the cerebellum or temporal lobe, respectively. Postoperative infection may result in meningitis or, if severe, cerebritis. CSF leak can sometimes be detected by identifying the presence of a fluid collection within or subjacent to the craniotomy site. Other complications such as $\mathrm{CN}$ deficits are better assessed by clinical examination.

Labyrinthine fenestration may present with postoperative hearing loss and can be evaluated with a dedicated CT of the temporal bones. Bony labyrinthine dehiscence, however, may not always correlate with hearing loss or vestibular symptoms. ${ }^{73}$ Decreased T2 signal within the vestibulocochlear complex on 3D SS-GRE imaging postsurgically may reflect membranous fenestration, microvascular injury to the cochlea, or labyrinthitis ossificans. The decrease in T2 signal has been correlated with postoperative hearing loss. ${ }^{73}$

\section{CONCLUSIONS}

VSs are benign neoplasms of the vestibulocochlear nerve sheath and are the most common CPA tumor. VS can be managed by surgical resection, radiation therapy, and observation, though only select patients are followed conservatively due to its association with hearing loss. The treatment objectives of VS have shifted from total resection to long-term tumor control with maximum functional preservation. Larger tumors of $>3 \mathrm{~cm}$ are generally surgically resected because radiation poses a risk of brain stem compression due to posttreatment edema. Smaller tumors may be treated with surgery or radiation. Lateral skull base approaches include the TL, RS, and MF and have been applied to other skull base and PF pathologies. Knowledge of the management options and objectives allows the radiologist to provide imaging findings pertinent to initial management and to recognize expected posttherapeutic findings and unexpected complications.

\section{ACKNOWLEDGMENTS}

We thank Nadezhda Kiriyak and Gwen Mack for their illustrations in this article.

Disclosures: Benjamin T. Crane-RELATED: Grant: National Institute on Deafness and Other Communication Disorders, Comments: R01 DC013580, K23 DC011298*; UNRELATED: Patents (Planned, Pending, or Issued): University of Rochester, Comments: B.T. Crane, "Methods and Systems for Rehabilitation of Vestibular Disorders," US Patent 9,167,998. Filed February 24, 2012. Issued October 27, 2015. Assignee University of Rochester.* *Money paid to the institution.

\section{REFERENCES}

1. Mahaley MS Jr, Mettlin C, Natarajan N, et al. Analysis of patterns of care of brain tumor patients in the United States: a study of the Brain Tumor Section of the AANS and the CNS and the Commission on Cancer of the ACS. Clin Neurosurg 1990;36:347-52 Medline

2. Gentry LR, Jacoby CG, Turski PA, et al. Cerebellopontine anglepetromastoid mass lesions: comparative study of diagnosis with MR imaging and CT. Radiology 1987;162:513-20 CrossRef Medline

3. House JW, Waluch V, Jackler RK. Magnetic resonance imaging in 
acoustic neuroma diagnosis. Ann Otol Rhinol Laryngol 1986;95: 16-20 CrossRef Medline

4. Curati WL, Graif M, Kingsley DPE, et al. MRI in acoustic neuroma: a review of 35 patients. Neuroradiology 1986;28:208-14 CrossRef Medline

5. Jackler RK, Shapiro MS, Dillon WP, et al. Gadolinium-DTPA enhanced magnetic resonance imaging in acoustic neuroma diagnosis and management. Otolaryngol Head Neck Surg 1990;102:670-77 CrossRef Medline

6. Kemink JL, Langman AW, Niparko JK, et al. Operative management of acoustic neuromas: the priority of neurologic function over complete resection. Otolaryngol Head Neck Surg 1991;104: 96-99 CrossRef Medline

7. Sughrue ME, Kaur R, Rutkowski MJ, et al. Extent of resection and the long-term durability of vestibular schwannoma surgery. J Neurosurg 2011;114:1218-23 CrossRef Medline

8. Samii M, Gerganov VM, Samii A. Functional outcome after complete surgical removal of giant vestibular schwannomas. J Neurosurg 2010;112:860-67 CrossRef Medline

9. Bloch O, Sughrue ME, Kaur R, et al. Factors associated with preservation of facial nerve function after surgical resection of vestibular schwannoma. J Neurooncol 2011;102:281-86 CrossRef Medline

10. Slatery WH. Neurofibromatosis type 2. Otolaryngol Clin North Am 2015;48:443-60 CrossRef

11. Sughrue ME, Yeung AH, Rutkowski MJ, et al. Molecular biology of familial and sporadic vestibular schwannomas: implications for novel therapeutics. J Neurosurg 2011;114:359-66 CrossRef Medline

12. Doyle KJ. Is there still a role for auditory brainstem response audiometry in the diagnosis of acoustic neuroma? Arch Otolaryngol Head Neck Surg 1999;125:232 CrossRef Medline

13. McBurney C, Starr MA. A contribution to cerebral surgery: diagnosis, localization and operation for removal of three tumors of the brain: with some comments upon the surgical treatment of brain tumors. Am J Med Sci 1893;55:361-87

14. Ballance C. Some Points in the Surgery of the Brain and Its Membranes. London: Macmillan; 1907

15. Van Eiselsberg A. Uber die chirurgische Behandlung der Hirntumoren. Trans Intl Cong Med 1913;7:209-17

16. Dandy WE. Ventriculography following the injection of air into the cerebral ventricles. Ann Surg 1918;68:5-11 CrossRef Medline

17. Beller AJ, Schwartz A. Pneumoencephalographic studies following complete removal of supratentorial lesions. Radiology 1953;61: 200-07 CrossRef Medline

18. Cushing H. The acoustic tumors. In: Intracranial Tumors. Springfield, Illinois: Charles C. Thomas; 1932:85-92

19. House WF. Surgical exposure of the internal auditory canal and its contents through the middle cranial fossa. Laryngoscope 1961;71: 1363-85 Medline

20. House WF. Transtemporal bone microsurgical removal of acoustic neuromas: evolution of transtemporal bone removal of acoustic tumors. Arch Otolaryngol 1964;80:731-42 CrossRef Medline

21. Delgado TE, Bucheit WA, Rosenholtz HR, et al. Intraoperative monitoring of facial muscle evoked responses obtained by intracranial stimulation of the facial nerve: a more accurate technique for facial nerve dissection. Neurosurgery 1979;4:418-21 CrossRef Medline

22. Leksell L. The stereotaxic method and radiosurgery of the brain. Acta Chir Scand 1951;102:316-19 Medline

23. Leksell L. A note on the treatment of acoustic tumours. Acta Chir Scand 1971;137:763-65 Medline

24. Kondziolka D, Lunsford LD, McLaughlin MR, et al. Long-term outcomes after radiosurgery for acoustic neuromas. N Engl J Med 1998; 339:1426-33 CrossRef Medline

25. Burrows EH. Positive contrast examination (cerebellopontine cisternography) in extrameatal acoustic neurofibromas. $\mathrm{Br} J$ Radiol 1969;42:902-13 CrossRef Medline

26. Hitselberger WE, House WF. Polytome-pantopaque: a technique for the diagnosis of small acoustic tumors: technical note. J Neurosurg 1968;29:214-17 CrossRef Medline
27. Smouha EE, Yoo M, Mohr K, et al. Conservative management of acoustic neuroma: a meta-analysis and proposed treatment algorithm. Laryngoscope 2005;115:450-54 CrossRef Medline

28. Stangerup SE, Caye-Thomasen P, Tos M, et al. Natural history of vestibular schwannoma. Otol Neurotol 2006;27:547-52 CrossRef Medline

29. Nikolopoulos TP, Fortnum H, O'Donoghue G, et al. Acoustic neuroma growth: systematic review of the evidence. Otol Neurotol 2010; 31:478-85 CrossRef Medline

30. Fucci MJ, Buchman CA, Brackmann DE, et al. Acoustic tumor growth: implications for treatment choices. Am J Otol 1999;20: 495-99 Medline

31. Sughrue ME, Yang I, Aranda D, et al. The natural history of untreated sporadic vestibular schwannomas: comprehensive review of hearing outcomes. J Neurosurg 2010;112:163-67 CrossRef Medline

32. Huang MJ, Kano H, Mousavi SH, et al. Stereotactic radiosurgery for recurrent vestibular schwannoma after previous resection. J Neurosurg 2016 Jul 29. [Epub ahead of print] CrossRef Medline

33. Chung WY, Pan DH, Lee CC, et al. Large vestibular schwannomas treated by gamma knife surgery: long-term outcomes. J Neurosurg 2010;113(suppl):112-21 CrossRef Medline

34. Mandl ES, Meijer OW, Slotman BJ, et al. Stereotactic radiation therapy for large vestibular schwannomas. Radiother Oncol 2010;95: 94-98 CrossRef Medline

35. Carlson M, Tveiten OV, Driscoll C, et al. Long-term quality of life in patients with vestibular schwannoma: an international multicenter, cross-sectional study comparing microsurgery, stereotactic radiosurgery, observation, and nontumor controls. J Neurosurg 2015;122:833-42 CrossRef Medline

36. Oghalai JS, Driscoll CL. Atlas of Neurotologic and Lateral Skull Base Surgery. Berlin: Springer; 2016:19-103

37. Madjid S, Cordula M. Management of $\mathbf{1 0 0 0}$ vestibular schwannomas (acoustic neuromas): hearing function in 1000 tumor resections. Neurosurgery 1997;40:248-62 CrossRef Medline

38. Samii M, Gerganov V, Samil A. Improved preservation of hearing and facial nerve function in vestibular schwannoma surgery via the retrosigmoid approach in a series of 200 patients. J Neurosurg 2006; 105:527-35 CrossRef Medline

39. Blevins NH, Jackler RK. Exposure of the lateral extremity of the internal auditory canal through the retrosigmoid approach: a radioanatomic study. Otolaryngol Head Neck Surg 1994;111:81-90 CrossRef Medline

40. Ruckenstein MJ, Harris JP, Cueva RA, et al. Pain subsequent to resection of acoustic neuromas via suboccipital and translabyrinthine approaches. Am J Otol 1996;17:620-24 Medline

41. Flickinger JC, Lunsford LD, Linskey ME, et al. Gamma knife radiosurgery for acoustic tumors: multivariate analysis of four year results. Radiother Oncol 1993;27:91-98 CrossRef Medline

42. Foote RL, Coffey RJ, Swanson JW, et al. Stereotactic radiosurgery using the gamma knife for acoustic neuromas. J Radiat Oncol Biol Phys 1995;32:1153-60 CrossRef Medline

43. Jacob JT, Pollock BE, Carlson ML, et al. Sterotatctic radiosurgery in the management of vestibular schwannoma and glomus jugulare: indications, techniques and results. Otolaryngol Clin North Am 2015;48:515-26 CrossRef Medline

44. Flickinger JC, Kondziolka D, Lunsford LD. Dose and diameter relationships for facial, trigeminal, and acoustic neuropathies following acoustic neuroma radiosurgery. Radiother Oncol 1996;41: 215-19 CrossRef Medline

45. Lunsford LD, Niranjan A, Flickinger JC, et al. Radiosurgery of vestibular schwannomas: summary of experience in 829 cases. J Neurosurg 2013;119:195-99 Medline

46. Roos DE, Potter AE, Zacest AC. Hearing preservation after low dose linac radiosurgery for acoustic neuroma depends on initial hearing and time. Radiother Oncol 2011;101:420-24 CrossRef Medline

47. Hasegawa T, Kida Y, Kato T, et al. Long-term safety and efficacy of stereotactic radiosurgery for vestibular schwannomas: evaluation 
of $\mathbf{4 4 0}$ patients more than $\mathbf{1 0}$ years after treatment with gamma knife surgery. J Neurosurg 2013;118:557-65 CrossRef Medline

48. Carlson ML, Jacob JT, Pollock BE, et al. Long-term hearing outcomes following stereotactic radiosurgery for vestibular schwannoma: patterns of hearing loss and variables influencing audiometric decline. J Neurosurg 2013;118:579-87 CrossRef Medline

49. Mousavi SH, Niranjan A, Akpinar B, et al. Hearing subclassification may predict long-term auditory outcomes after radiosurgery for vestibular schwannoma patients with good hearing. J Neurosurg 2016;125:845-52 CrossRef Medline

50. Jacob JT, Carlson ML, Schiefer TK, et al. Significance of cochlear dose in the radiosurgical treatment of vestibular schwannoma: controversies and unanswered questions. Neurosurgery 2014;74: 466-74; discussion 474 CrossRef Medline

51. Akpinar B, Mousavi SH, McDowell MM, et al. Early radiosurgery improves hearing preservation in vestibular schwannoma patients with normal hearing at the time of diagnosis. Int J Radiat Oncol Biol Phys 2016;95:729 CrossRef Medline

52. Sarrazin JL. Infra tentorial tumors [in French]. J Radiol 2006;87: 748-63 Medline

53. Matthies C, Samii M, Krebs S. Management of vestibular schwannomas: radiological features in 202 cases. Neurosurgery 1997;40:469-81; discussion 481-82 Medline

54. Piccirillo E, Wiet MR, Flanagan S, et al. Cystic vestibular schwannoma: classification, management and facial nerve outcomes. Otol Neurotol 2009;30:826-34 CrossRef Medline

55. Pendl G, Ganz JC, Kitz K, et al. Acoustic neurinomas with macrocysts treated with gamma knife radiosurgery. Stereotact Funct Neurosurg 1996;66:103-11 Medline

56. Benech F, Perez R, Fontanella MM, et al. Cystic versus solid vestibular schwannomas: a series of $\mathbf{8 0}$ grade III-IV patients. Neurosurg Rev 2005;28:209-13 CrossRef Medline

57. Delsanti C, Régis J. Cystic vestibular schwannomas [in French]. Neurochirurgie 2004;50:401-06 Medline

58. Goddard J, Schwartz M, Friedman R. Fundal fluid as a predictor of hearing preservation in the middle cranial fossa approach for vestibular schwannoma. Otol Neurotol 2010;31:1128-34 CrossRef Medline

59. Somers T, Casselman J, de Ceulaer G, et al. Prognostic value of magnetic resonance imaging findings in hearing preservation surgery for vestibular schwannoma. Otol Neurotol 2001;22:87-94 CrossRef Medline

60. Abele TA, Besachio DA, Quigley EP, et al. Diagnostic accuracy of screening MR imaging using unenhanced axial CISS and coronal T2WI for detection of small internal auditory canal lesions. AJNR Am J Neuroradiol 2014;35:2366-70 CrossRef Medline

61. Bhadelia RA, Tedesco KL, Hwang S, et al. Increased cochlear fluid- attenuation inversion recovery signal in patients with vestibular schwannomas AJNR Am J Neuroradiol 2008;29:720-23 CrossRef Medline

62. Lee IH, Kim HJ, Chung WH, et al. Signal intensity change of the labyrinth in patients with surgically confirmed or radiologically diagnosed vestibular schwannoma on isotropic 3D fluid-attenuated inversion recovery MR imaging at 3 T. Eur Radiol 2010;20: 949-57 CrossRef Medline

63. Yoshida T, Sugiura M, Naganawa S, et al. Three-dimensional fluidattenuated inversion recovery magnetic resonance imaging findings and prognosis in sudden sensorineural hearing loss. Laryngoscope 2008;118:1433-37 CrossRef Medline

64. O'Connor AF, France MW, Morrison AW. Perilymph total protein levels associated with cerebellopontine angle lesions. Am J Otol 1981;2:193-95 Medline

65. Kim DY, Lee JH, Sung YS, et al. Clinical significance of an increased cochlear 3D fluid-attenuated inversion recovery signal intensity on an MR imaging examination in patients with acoustic neuroma. AJNR Am J Neuroradiol 2014;35:1825-29 CrossRef Medline

66. Yamazaki M, Naganawa S, Kawai $\mathrm{H}$, et al. Increased signal intensity of the cochlea on pre- and post-contrast enhanced 3DFLAIR in patients with vestibular schwannoma. Neuroradiology 2009;51:855-63 CrossRef Medline

67. Committee on Hearing and Equilibrium guidelines for the evaluation of hearing preservation in acoustic neuroma. Otol Head Neck Surg 1995;113:179-80 CrossRef Medline

68. Kanzaki J, Tos M, Sanna M, et al. New and modified reporting systems from the consensus meeting on systems for reporting results in vestibular schwannomas. Otol Neuotol 2003;24:42-48; discussion 648-49 Medline

69. Walsh RM, Bath AP, Bance ML, et al. Comparison of two radiologic methods for measuring the size and growth rate of extracanalicular vestibular schwannomas. Am J Otol 2000;21:716-21 Medline

70. Nagano O, Higuchi Y, Serizawa T, et al. Transient expansion of vestibular schwannoma following stereotactic radiosurgery. J Neurosurg 2008;109:811-16 CrossRef Medline

71. Delsanti C, Roche PH, Thomassin JM, et al. Morphological changes of vestibular schwannomas after radiosurgical treatment: pitfalls and diagnosis of failure. Prog Neurol Surg 2008;21:93-97 CrossRef Medline

72. Park CK, Kim DC, Park SH, et al. Microhemorrhage, a possible mechanism for cyst formation in vestibular schwannomas. $\mathrm{J} \mathrm{Neu-}$ rosurg 2006;105:576-80 CrossRef Medline

73. Warren FM 3rd, Kaylie DM, Aulino JM, et al. Magnetic resonance appearance of the inner ear after hearing-preservation surgery. Otol Neurotol 2006;27:393-97 CrossRef Medline 